\title{
Surgical Anatomy of the Inguinal Region: Implications during Inguinal Laparoscopic Herniorrhaphy
}

\author{
E. Totté ${ }^{a} \quad$ R. Van Hee ${ }^{a} \quad$ G. Kox ${ }^{a} \quad$ L. Hendrickx ${ }^{a} \quad$ K.J. van Zwieten ${ }^{b}$ \\ ${ }^{a}$ Academic Surgical Center Stuivenberg, General Centrum Hospital Antwerp, University of Antwerp, Antwerp, \\ and ${ }^{b}$ Department of Anatomy, University Center of Limburg, Diepenbeek, Belgium
}

\section{Key Words}

Hernia repair, laparoscopic $\cdot$ Inguinal region ·

Herniorrhaphy · Laparoscopy, complications

\begin{abstract}
Introduction: In laparoscopic inguinal hernia repair the inguinal region is approached and hernia repair performed from the interior side instead of the classical open external access. Exploration and placement of staplers in the internal inguinal region during laparoscopic hernia repair may sever different anatomical structures, or induce specific complications such as nerve entrapment, neuralgia, hematomas or osteitis. The incidence of these complications may be reduced by careful dissection of the preperitoneal tissues and by placing a prosthetic mesh without the use of stapling. As laparoscopic techniques evolved, different sizes of meshes have been used. An exact determination of mesh size was hitherto not investigated. Aim: Cadaver studies of the topography of blood vessels and nerves in the preperitoneal tissue in this region were carried out in order to assess a safe position and adequate size of the prosthetic mesh. Methods: Dissection in 6 preserved human female cadavers was performed to define the actual surface of the internal inguinal region. A physical model was
\end{abstract}

developed to formulate the ideal size of the prosthesis. Specific measurements were used to define the maximal size of the meshes, so as to place them without stapling, and without inducing neurovascular complications. $\boldsymbol{R e}$ sults: The designed physical formula defines the size of the mesh as a function of the maximum intra-abdominal pressure, the size of the abdominal wall defect and the abdominal wall tension. Conclusion: On mathematical and physical grounds our study points out that the size of the currently used prosthetic mesh $(10 \times 15 \mathrm{~cm})$ is large enough to be placed without stapling so that with proper placement no recurrences should occur.

Copyright $(\underset{2}{2005}$ S. Karger AG, Basel

\section{Introduction}

Within the field of laparoscopic procedures hernia repair has become a well-accepted intervention. There are still specific avoidable complications which are inherent to the laparoscopic procedure. During laparoscopic inguinal hernia repair, the preperitoneal space is entered in a transabdominal (transabdominal preperitoneal) or in a totally preperitoneal (totally extraperitoneal) manner. The parietal peritoneum is released in the surrounding area of the internal inguinal ring and a prosthetic mesh is

\section{KARGER}

Fax +4161306 1234 E-Mail karger@karger.ch www.karger.com
(C) 2005 S. Karger AG, Basel

0014-312X/05/0373-0185\$22.00/0

Accessible online at: www.karger.com/esr
Prof. Dr. R. Van Hee

Academic Surgical Center Stuivenberg

Algemeen Centrum Ziekenhuis Antwerpen, Lange Beeldekensstraat 267 BE-2060 Antwerpen (Belgium)

Tel. +32 32177 235, Fax +32 32177 254, E-Mail robrecht.vanhee@zna.be 
placed in the preperitoneal space covering the hernia to reinforce the abdominal wall. To prevent recurrences the mesh is frequently fixed with staplers on the preperitoneal tissue [1-5].

Specific complications due to laparoscopic hernia repair have been well documented. Creation of a pneumoperitoneum either by a needle or by an open trocar technique can lead to hematoma, intestinal perforation or vascular injuries. Pulmonary and cardiovascular effects of the sustained gaseous distention have also been documented [4].

Complications resulting from the hernia repair itself $[1,6-14]$, such as scrotal or abdominal wall subcutaneous emphysema, scrotal hematoma, wound infection or the occurrence of recurrences, are not specifically related to the anatomical structures and fall beyond the scope of this study.

On the contrary, complications resulting from an inadequate knowledge of the anatomy of the internal inguinal region are of major interest [11,15-21].

Meralgia paresthetica or neuralgia as a result of nerve entrapment by placing fixating staplers is directly related to the anatomical position of certain structures $[6,7,9$, 14, 19-21].

Hematomas may occur by careless dissection of the preperitoneal space or placing the staplers. Moreover fixation of the mesh on the pubic arch may occasionally lead to severe disabling osteitis [1, 10]. Adequate knowledge of the anatomical structures in the internal inguinal region may reduce the incidence of these complications. By far the best way to avoid this morbidity is by placing the prosthetic mesh without stapling [22].

As recurrences may occur if the prosthesis is not fixed with staples, another method to avoid recurrences is necessary. Increasing the size of the mesh is a possible alternative to obtain a successful and reliable hernia repair.

Surgical textbooks and literature on laparoscopic operative techniques give incomplete information about the actual form of the internal inguinal region and the size of the prosthetic mesh.

In this investigation, cadaver studies of the topography of blood vessels and nerves in the preperitoneal inguinal region were undertaken in order to assess the adequate position and size of the prosthetic mesh. Moreover a physical and mathematical model was developed to define, on theoretical basis, the most suitable prosthesis size to be used.

\section{Methods}

An extensive study of the regional anatomy of the internal inguinal region was performed by dissecting 6 female cadavers with a mean length of 168 (range 161-178) $\mathrm{cm}$. To obtain a precise identification of the anatomical structures during dissection, the anterior abdominal wall was left untouched. Indeed, the inguinal region is dissected from the intra-abdominal side, instead of the external side, by using a preperitoneal approach. The parietal peritoneum is then pushed off the preperitoneal adipose tissue by blunt dissection, continuing in all directions to the deep inguinal ring. Subsequently, all important anatomical structures are identified.

Different attitudes have been adopted for the left and right inguinal region. On the left body side, deep sharp dissection enables identification of all blood vessels and nerves in the inguinal region. The findings are compared with the literature.

On the right body side, only the preperitoneal adipose tissue is removed to study the mutual relationship. Eight radio-opaque markings delineate the different anatomical structures and possible hernia regions (indirect inguinal, direct inguinal, supravesical and femoral) (fig. 1).

Two X-rays were taken from each cadaver: one frontal plane exposure, and one lateral exposure. The radiographs were analyzed electronically. The distances between the different marks were measured and reprinted in actual size to define the real size of the surface of the internal inguinal region and to calculate the minimal size of the mesh.

By means of classical physical methods, a model was then developed to formulate the ideal size of the prosthesis, with the aim of placing it without stapling and preventing neurovascular complications.

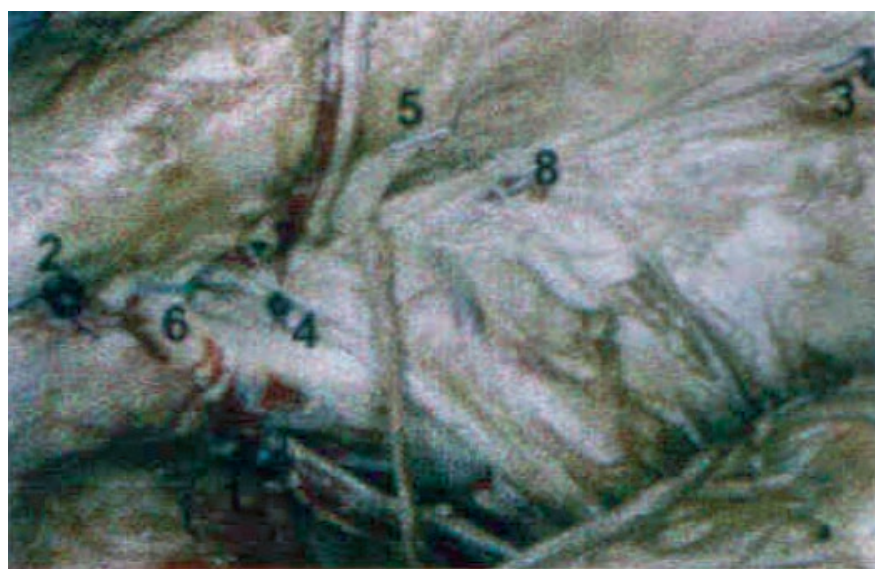

Fig. 1. Radio-opaque markings delineating the anatomical structures and hernia sites. 1 = Obturator canal; 2 = pubic tuberculum; 3 = ileopubic tract; $4=$ right superior pubis; $5=$ upper limit interfoveolar ligament; 6 = medial ending ileopubic tract (medial of femoral canal); 7 = crossing of inferior epigastric artery, veins and ileopubic tract; 8 = lateral ending of arc of transverse abdominal muscle. 


\section{Results}

\section{Safe Position and Adequate Size of the Prosthesis}

Both the position and size of the mesh aim to cover various loci of minor resistance in the entire inguinal region. The measured surface of the different possible herniation sites in the inguinal region (supravesical, direct and indirect inguinal, and femoral) constitutes the minimal surface of a prosthesis. In order to place a mesh without fixation with staplers, the prosthesis should be larger than this minimal surface.

As can be seen in figure 2, various triangles may be drawn in the inguinal region. Triangle A defines the surface of the supravesical and direct inguinal hernias. Triangle $B$ represents the surface of the indirect hernia, and triangle $C$ contains femoral hernias. Quadrangle D represents the minimum surface to cover the different hernias, including the obturator canal.

By adding the different triangles, the minimal surface of the prosthesis may be calculated as $\mathrm{S}_{\min }=\mathrm{A}+\mathrm{B}+\mathrm{C}=$ $16 \pm 4 \mathrm{~cm}^{2}$. The surface of quadrangle $D$ is calculated as an actual surface of $\pm 36 \mathrm{~cm}^{2}$.

To position a rectangular prosthesis over this area and cover the whole inguinal region, the dimensions should at least be $8 \times 9 \mathrm{~cm}$, e.g. $72 \mathrm{~cm}^{2}$. Part of this $\left(36 \mathrm{~cm}^{2}\right)$ lies upon possible hernia sites, while part lies on the abdominal wall and may provide anchoring. The size of the currently used prosthetic mesh $(10 \times 15 \mathrm{~cm})$ may thus be too large, and can easily be placed without stapling as enough anchoring zone is provided.

\section{Physical Model: Estimation of the Ideal Size of the}

\section{Prosthesis}

One may estimate that the abdominal wall, the hernia site and the mesh have a semi-lunar shape. On a circular defect in the abdominal wall, covered by the prosthesis (fig. 3), a centrifugal pressure force is exerted by the intraabdominal pressure on each infinitesimal small part of the mesh. This force is counteracted by the surface tension of the mesh. Considering the entire abdominal wall, by substitution one can deduce a formula to identify the size of the mesh.

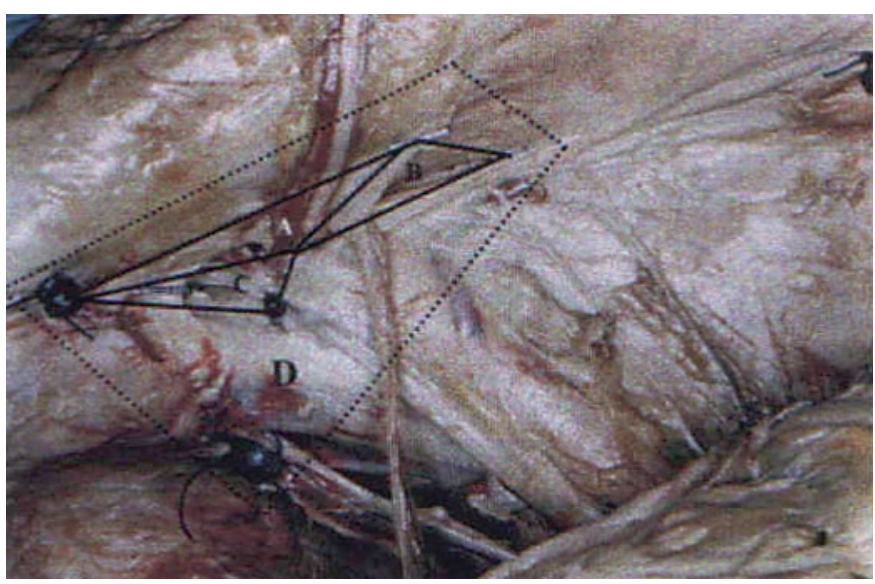

Fig. 2. Hernia site surface.
Fig. 3. Physical determination of the forces exerted by intra-abdominal pressure and counteracted by the tension of the mesh.

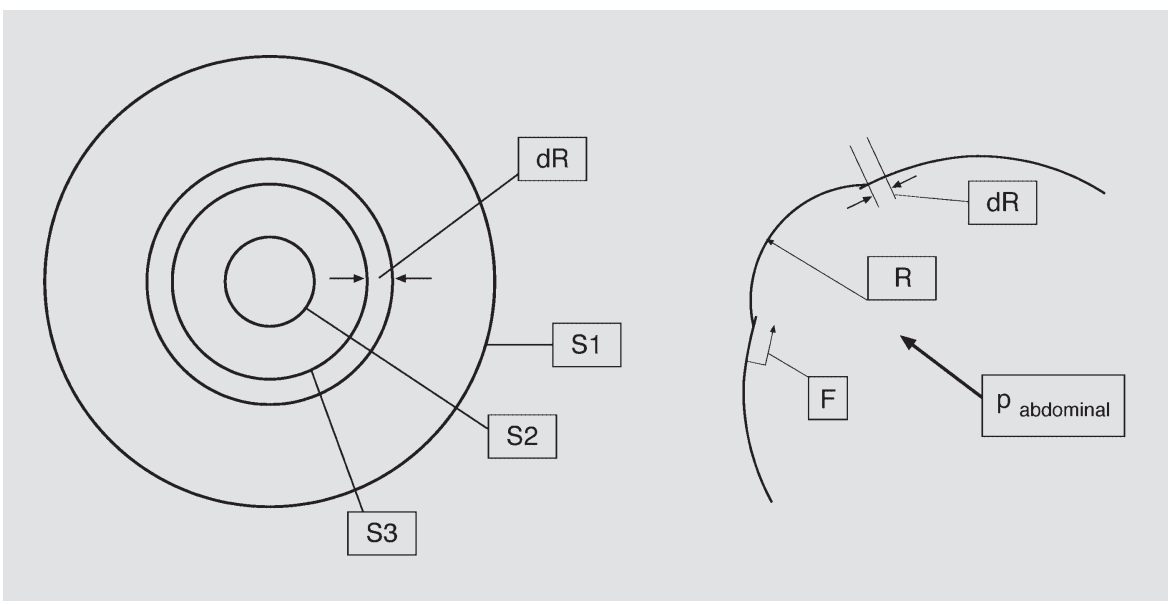


Indeed, according to the law of Laplace, the abdominal pressure $p_{\text {abd.max }}$ will exert a force on the mesh inner surface, equally distributed over the anchored surface covering the abdominal wall, and the center of the mesh covering the defect.

At an abdominal pressure $\mathrm{p}_{\mathrm{abd} \text { max }}$ the prosthesis will not stretch over the defect, but adopt a semi-spherical shape with radius $\mathrm{R}$, whereby a displacement of the mesh over the abdominal wall will occur in the direction of the defect over a distance $\mathrm{dR}$, reducing the anchored surface under tension to a surface S3. Because of this displacement, a particular tension force is exerted on the anchoring surface of the prosthesis.

This force $\mathrm{F}$, exerted on the bent prosthesis, equals $\mathrm{p}_{\mathrm{abd} \text {.max }} \times \Pi \mathrm{R}^{2}$, and corresponds with a force exerted on an infinitesimal surface $\mathrm{dS}$, with the same radius $\mathrm{R}$.

Wall tension, expressed as the work exerted on such an infinitesimal surface, $\mathrm{dW}$, can be defined as $\mathrm{dW}=$ $\lambda \times \mathrm{dS}, \lambda$ representing the specific wall characteristics of the patient.

This work load can therefore be calculated in two ways, either expressed in relation to the radius: $\mathrm{W}(\mathrm{R})=$ $f \mathrm{~F}(\mathrm{R}) \mathrm{dR}=\mathrm{p}_{\mathrm{abd} \text { max }} \times 1 / 3 \pi \mathrm{R}^{3}$, or in relation to the surface $\left(S\right.$ equaling $\left.\pi R^{2}\right)$ : $W(S)=p_{\text {abd.max }} \times 1 / 3 \pi \times$ $(\mathrm{S} / \pi)^{3 / 2}$.

For calculating maximal wall tension, the following formula can therefore be used:

$$
\mathrm{S}_{1} \times \lambda_{\text {abd.wall }}=\mathrm{p}_{\mathrm{abd} \text { max }} \times 1 / 3 \pi \times\left[\left(\mathrm{S}_{2}+\mathrm{S}_{3}\right) / \pi\right]^{3 / 2}
$$

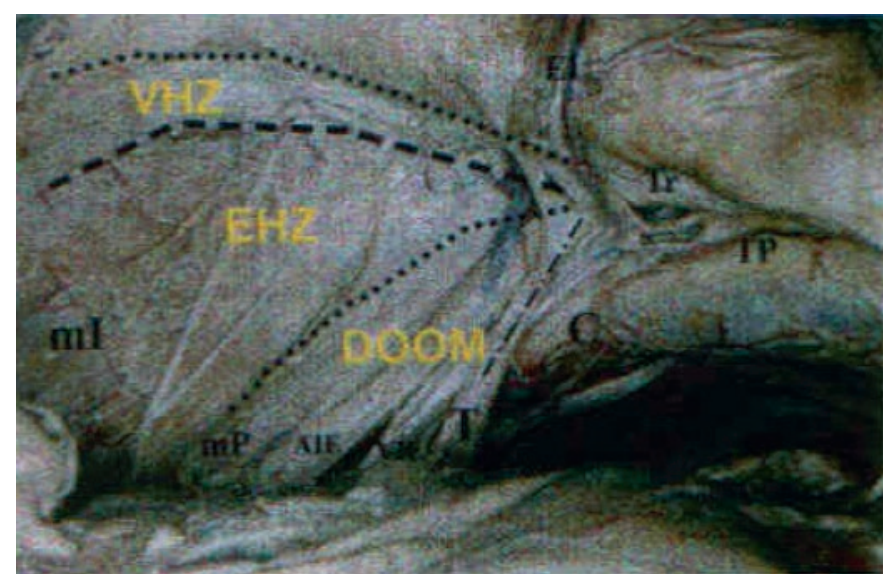

Fig. 4. The various regions of danger, including the triangle of doom. $\mathrm{VHZ}=$ Vascular hazard zone; $\mathrm{EHZ}=$ electrical hazard zone; Doom = triangle of doom; EI: inferior epigastric artery and vein; $\mathrm{Tr}=$ ileopubic tract; $\mathrm{TP}=$ pubic tuberculum; $\mathrm{C}=$ Cooper's ligament; $\mathrm{T}=$ ligament of Teres; A-Vie = external iliac artery and vein; $\mathrm{mI}=$ iliac muscle; $\mathrm{mP}=$ psoas muscle. with: $\mathrm{S}_{1}=$ the size of the prosthesis; $\mathrm{S}_{2}=$ the size of the abdominal wall defect or hernia; $\mathrm{S}_{3}=$ anchoring zone; $\lambda_{\text {abd.wall }}=$ parameter in function of abdominal wall characteristics; $\mathrm{p}_{\mathrm{abd} \text { max }}=$ maximum intra-abdominal pressure.

The abdominal wall resistance coefficient $(\lambda)$ remains an individual parameter not yet defined in humans. However, Horgan et al. [23] determined such parameters in pigs, and stated them to be comparable to the human situation. Using the cited physical formula, one may calculate that even very high abdominal pressures $\left(p_{\text {abd.max }}\right)$ can be safely exerted with the meshes commonly used today $\left(S_{1}=10 \times 15 \mathrm{~cm}=150 \mathrm{~cm}^{2}\right)$, which provide large surfaces of anchoring zone $\left(\mathrm{S}_{3}=150-\right.$ $72 \mathrm{~cm}=78 \mathrm{~cm}^{2}$ ) over the largest possible hernia surface $\left(\mathrm{S}_{2}=72 \mathrm{~cm}^{2}\right)$.

\section{Discussion}

\section{Anatomical Areas and Structures in the Dissected Region}

Both Spaw [18] and Rosser [17] have given a description of the inguinal anatomy from the laparoscopic point of view, and divided the inguinal region into various 'regions of danger' (fig. 4).

The vas deferens and the gonadal vessels form the boundaries of a so-called 'triangle of doom' [18]. This triangle of doom contains the external iliac artery and vein. No dissection or other activity whatsoever should be performed in this area, as an injury to either of these vessels could be fatal. Moreover the genital branch of the genitofemoral nerve lies in this area and is equally in danger in case of careless dissection [18].

Lateral to the spermatic vessels is an area referred to as the 'electrical hazard zone' [17]. It is aponeurotic in appearance and contains different neural structures. The iliacus muscular fascia covers the femoral nerve as well as small branches to the iliacus muscle, the pectineus muscle and the femoral artery. Lateral to the femoral nerve, the lateral femoral cutaneous nerve is equally covered by the iliacus fascia. This nerve crosses the area and passes through the ileopubic tract medial to the anterior superior iliac spine. Especially these structures are easily injured when stapling the lateral inferior corner of the mesh. Any injury to this nerve can cause neuralgia or meralgia paresthetica [17].

At the superior aspect of the electrical hazard zone and paralleling the ileopubic tract lie the deep circumflex iliac artery and vein. These vessels may be injured by applying 
staplers to the ileopubic tract. This area therefore is called the 'vascular hazard zone' [17].

\section{Laparoscopic Consequences}

Although laparoscopic procedures for hernia repair are well accepted, there are still complications inherent to the procedure, such as neuralgia and meralgia paresthetica as a result of nerve entrapment, as well as osteitis of the pubis by placing fixating staplers. However, if the prosthesis is not stapled, recurrences may occur. Increasing the size of the mesh is an acceptable alternative to prevent such local recurrence. However, meralgia paresthetica caused by entrapment in fibrous tissue may still occur.

Reasons for hernia recurrence are multiple: usage of too small a prosthesis leading to incomplete coverage of all herniation sites [22], and incomplete dissection of the hernial sac [3]. Insufficient medial coverage may lead to rolling up of the prosthesis from the medial side, and uncovering the hernial region. This may be avoided by changing the pliability of the material used. Making the prosthesis less pliable would, however, make it more difficult to handle. With increasing experience, these complications should nevertheless disappear spontaneously [16].

The exact size of the mesh was hitherto not scientifically investigated and was only based on practical experience. The specific measurements on preserved cadavers give a practical idea of the surface of the inguinal region. A prosthesis of $8 \times 9 \mathrm{~cm}$ is large enough to cover the whole inguinal region. As an anchoring zone is needed, one can say that the prosthetic mesh $(10 \times 15 \mathrm{~cm})$ currently used is large enough to cover the complete inguinal region in a safe manner. Moreover the method used enables an early decision on the size of mesh needed in a certain individual (android or gynecoid pelvis, young or elderly).

The physical formula leads to a more exact size of the mesh. It shows that the more anchoring surface the mesh has, the more resistance the mesh can offer to the intraabdominal pressure. As long as the prosthesis is not fixed by fibrous tissue, the prosthesis will slide into the abdominal wall defect as soon as the abdominal pressure increases, and a recurrence will be the result. Therefore at this stage the changes in intra-abdominal pressure, the size of the original abdominal wall defect and the coefficient of friction are the most important factors which define the success of the operation. Once the prosthesis is fixed by ingrowth of fibrous tissue, the most important factor will be the lateral pulling forces on the anchoring zone. Horgan et al. [23] investigated the magnitude of these forces in pigs.

Analogous investigations in humans cannot be done because of the mutilating character of the research, but could probably be estimated by this physical model. Once the prosthesis is fixed by fibrous tissue, recurrences will only appear if the prosthesis is torn from the abdominal wall (defined by the quality of the fibrous tissue), if the abdominal wall ruptures or if the position of the prosthesis is not anatomically correct [23].

In case of very large hernias or recurrences, it could be useful to combine different techniques of hernial repair (for example mesh and plug method).

\section{Conclusion}

On mathematical and physical grounds, this study confirms that the size of the prosthetic mesh $(10 \times 15 \mathrm{~cm})$ currently used is large enough to be placed without stapling, and that with proper placement no recurrences should occur. Different complications, such as neuralgia or meralgia paresthetica by nerve entrapment or osteitis, can be avoided by not fixing the prosthesis. The designed physical formula defines the size of the mesh as a function of the maximum intra-abdominal pressure, the size of the abdominal wall defect and the wall tension. Once the prosthesis is fixed by growth of fibrous tissue, recurrences will only appear if the position of the prosthesis is not anatomically correct, if the abdominal wall defect is too large in comparison to the size of the prosthesis (the prosthesis will be torn from the abdominal wall) or if a new abdominal wall defect exists next to the prosthesis. 


\section{References}

$\checkmark 1$ Cornel RBI, Kerlakian GM: Early complications and outcomes of the current technique of transperitoneal laparoscopic herniorraphy and a comparison to the traditional open approach. Am J Surg 1994; 168:275-279.

$>2$ Felix EL, Michas CA, Gonzalez MH Jr: Laparoscopic hernioplasty, TAPP vs. TEP. Surg Endosc 1995;9:984-989.

$\checkmark 3$ Liem MSL, van Vroonhoven TJMV: Laparoscopic inguinal hernia repair. Br J Surg 1996; 83:1197-1204.

-4 McKernan JB, Laws HL: Laparoscopic repair of inguinal hernias using a totally extraperitoneal prosthetic approach. Surg Endosc 1993;7: 26-28.

$\checkmark 5$ McKernan JB: Extraperitoneal prosthetic inguinal hernia repair using an endoscopic approach. Int Surg 1995;80:26-28.

-6 Andrew DR, Gregory RP, Richardson DR: Meralgia paraesthetica following laparoscopic inguinal herniorrhaphy. Br J Surg 1994;81: 715.

7 Annabali R, Quinn T, Fitzgibbons RJ Jr: Avoiding nerve injury during laparoscopic hernia repair: Critical areas for staple placement; in Arregui ME, Nagan RF (eds): Inguinal Hernia: Advances or Controversies? Abingdon, Radcliffe Medical Press, 1994, pp 41-50.

$>8$ Arregui ME, Navarrete J, Davis CJ, Castro D, Nagan RF: Laparoscopic inguinal herniorraphy. Techniques and controversies. Surg Clin North Am 1993;73:513-527.
-9 Broin EO, Horner C, Mealy K, Kerin MJ, Gillen P, O'Brien M, Tanner WA: Meralgia paraesthetica following laparoscopic inguinal hernia repair - An anatomical analysis. Surg Endosc 1995;9:76-78.

10 Condon RE, Nyhus LM: Complications of groin hernia; in Nyhus LM, Condon RE (eds): Hernia, ed 4. Philadelphia, Lippincott, 1995, pp 269-282.

11 Gilbert AI: Pitfalls and complications of inguinal hernia repair; in Arregui ME, Nagan RF (eds): Inguinal Hernia: Advances or Controversies? Abingdon, Radcliffe Medical Press, 1994, pp 205-212.

12 MacFadyen BV: Laparoscopic inguinal herniorraphy: Complications and pitfalls; in Arregui ME, Nagan RF (eds): Inguinal Hernia: Advances or Controversies? Abingdon, Radcliffe Medical Press, 1994, pp 289-296.

13 Phillips EH, Rosenthal R, Fallas M, Carroll B, Arregui M, Corbitt J, Fitzbibbons R, Seid A, Schultz L, Toy F, Wadell R, McKernan B: Reasons for early recurrence following laparoscopic hernioplasty. Surg Endosc 1995;9:140-145.

14 Sampath P, Yeo CJ, Campbell JN: Nerve injury associated with laparoscopic inguinal herniorraphy. Surgery 1995;118:5:829-833.

15 Kraus MA: Laparoscopic identification of preperitoneal nerve anatomy in the inguinal area. Surg Endosc 1994;8:377-381.

16 Liem MSL, van Steensel CJ, Boelhouwer RU, Weidema WF, Clevers G-J, Meijer WS, Vente JP, de Vries LS, van Vroonhoven TJMV: The learning curve for totally extraperitoneal laparoscopic inguinal hernia repair. Am J Surg 1996; 171:281-285.
17 Rosser J: The anatomical basis for laparoscopic hernia repair revisited. Surg Laparosc Endosc 1994;4:36-44.

18 Spaw A: Laparoscopic hernia repair: The anatomic basis. J Laparoendosc Surg 1991;1:269277.

19 van Mameren H, Go PMNYH: Surgical anatomy of the interior inguinal region, consequences for laparoscopic hernia repair. Surg Endosc 1994;8:1212-1215.

20 van Mameren H, Go PMNYH: Safe areas for mesh stapling in laparoscopic hernia repair; in Arregui ME, Nagan RF (eds): Inguinal Hernia: Advances or Controversies? Abingdon, Radcliffe Medical Press, 1994, pp 483-487.

21 van Mameren H, Beets GL, Go PMNYH: De regio inguinalis van binnenuit ontleed. Ned Tijdschr Heelk 1995;4:187-191.

22 Van Steensel CJ, Weidema WF: Laparoscopic inguinal hernia repair without fixation of the prosthesis; in Arregui ME, Nagan RF(eds): Inguinal Hernia: Advances or Controversies? Abingdon, Radcliffe Medical Press, 1994, pp 435-436.

23 Horgan LF, Shelton JC, O'Riordan DC, Moore DP, Winslet MC, Davidson BR: Strengths and weaknesses of laparoscopic and open mesh inguinal hernia repair: A randomized controlled experimental study. Br J Surg 1996,83:14631467. 